\title{
Coming and going
}

\section{Geoffrey Norman ${ }^{1}$}

๑) Springer Nature B.V. 2019

I have been editor in chief of AHSE for nearly 25 years now. Not surprisingly, over that period of time I have seen many people join our editorial board, and then, for one reason or another, move on to other challenges.

Usually this occurs one at a time and is hardly newsworthy. However recently a number of people who have collectively served for decades on the Board, have decided the time has come to move on. Concurrently, AHSE is in the middle of another growth spurt. For several years, submissions have been fairly stable. However, last year the number of submissions rose by $20 \%$, and it is on track to do the same this year.

Some other statistics:

We just received our impact factor from Clarivate. IF for 2018 is 2.761 , a gain of .20 over last year. We are ranked in the top $1 / 4$ of educational research journals worldwide.

Well, first the departures:

Richard Marz, University of Vienna

Vanessa Burch, University of Capetown

Lambert Schuwirth, Flinders

Kevin McLaughlin, University of Calgary

And not so recently:

Clare Kreiter, University of Iowa

Bill McGaghie, Northwestern University

All of these individuals have been on the Board for many years and have made a major contribution to the Journal. They will be missed. My sincere and personal thanks to all of them for their hard work.

Well the combination of increased demand and fewer editors could amount to a perfect storm. So we have been shaking the trees to find new editors. Fortunately, we did not have to shake too many too hard. We are very pleased to have six new associate editors from 5 countries joining us. They are:

Geoffrey Norman

norman@mcmaster.ca

1 McMaster University, Hamilton, ON, Canada 


\section{H. Carrie Chen, MD, Ph.D.}

Carrie Chen is the Associate Dean of Assessment and Educational Scholarship and Professor of Pediatrics at Georgetown University School of Medicine, and Adjunct Professor of Medicine at the Uniformed Services University of the Health Sciences.

She completed her Doctor of Medicine and pediatric residency and chief residency at the University of California San Francisco (UCSF) School of Medicine. She subsequently obtained a Master of Science in Education from the University of Southern California Rossier School of Education and a Doctorate in Health Professions Education from Utrecht University in the Netherlands.

She was previously a member of the UCSF Academy of Medical Educators and held the Abraham Rudolph Endowed Chair in Pediatric Education. She has experience in curriculum development and program leadership in student, resident, and fellow education as well as continuing medical education and faculty development. Her research interests include workplace learning, workplace-based assessments including the use of entrustable professional activities (EPAs), and faculty skill development and support.

\section{Martin R. Fischer, MD, MME, FAMEE}

Martin Fischer is a general internist and endocrinologist. Since August 2011 he is full professor and Director of the Institute for Medical Education at the University Hospital of Ludwig-Maximilians-University (LMU) Munich.

$\mathrm{He}$ received his undergraduate and medical education in Hamburg and Freiburg, Germany. He did graduate studies at Royal Free Hospital, London, UK, Kantonsspital, Lucerne, Switzerland, and Dartmouth Medical Center, Lebanon (NH), USA.

He received his Master of Medical Education (MME) degree at the University of Berne, Switzerland, and is also certified in Medical Informatics. Since 2004 he is CoDirector of the German national Master of Medical Education (MME) program.

He has led various international projects for computer applications to medical education and assessment including development of the CASUS virtual patient learning system. CASUS provides the software platform for the widely adopted MedU suite of virtual patient courses. He has received numerous grants and research awards and has co-authored more than 170 published articles and book chapters.

\section{Mahan Kulasegaram, Ph.D.}

Dr. Kulasegaram (Mahan)'s research examines educational assessment from both a psychometric and cognitive perspective. His work aims to advance assessment theory and practice by conceptualizing assessment as an instructional and advancement opportunity. This involves re-examining the entire context of assessment-the objectives, process, tools, learners, and raters-from theoretical perspectives informed by cognitive theory and best evidence on measurement. His other interests also include the role of working memory in decision making and learning in healthcare as well as 
the application of cognitive theory to instructional design and practice. Additionally, he dabbles in applying novel and advanced statistical methods to large data sets.

Mahan joined the Wilson Centre in 2013. Previously, he was a graduate fellow from 2009 to 2013 and a post-doctoral fellow in 2013. He completed his Ph.D. in the Department of Clinical Epidemiology and Biostatistics and in the Program for Educational Research and Development at McMaster University in 2013. He is currently an Assistant Professor in the Department of Family and Community Medicine at the University of Toronto and is the Evaluation Scientist in Undergraduate Medical Education. He has 50 publications in health professions education.

\section{Maria Athina (Tina) Martimianakis, Ph.D.}

Tina Martimianakis is the Director of Medical Education Scholarship and an Education Researcher in the Department of Paediatrics, University of Toronto. She holds a Masters in Political Science, from Wilfrid Laurier University, a Masters in Education with a focus on health professional education and a Doctorate in Higher Education, both from the Ontario Institute for Studies in Education. Tina also completed a Fellowship in Medical Education at the Wilson Centre, sponsored through the Department of Psychiatry. Drawing on critical social science theories and Foucauldian discourse analysis, Tina studies the interface of discourse, governance and identity in clinical contexts.

She is currently researching how organizational practices support or hinder the capacity of interprofessional teams to practice and learn together. As well, she is exploring how discourses of integration manifest in every day medical education practices. Previous work has explored interdisciplinary as a process of knowledge production and globalization and its relationship to medical competency.

Tina is an active teacher and program developer and contributes to the enhancement of education scholarship within the Departments of Paediatrics, Psychiatry and the Faculty of Medicine more broadly. She has more than 40 publications.

\section{Stephen Maloney, Ph.D.}

Stephen Maloney (B.Physio, MPH, PhD, eMBA) is the Deputy Head of School, and Director of Education for Monash University's School of Primary and Allied Health Care, in the Faculty of Medicine, Nursing and Health Sciences. Stephen is a founding member and current chair of the International Society for Cost and Value in Health Professions Education, a fellow of the Monash Education Academy, and an adjunct of the Monash Education and Research Quality Unit. Stephen's education and research interests are predominantly in the area of cost and value-looking at not only what works... but at what cost—with the goal of increasing the evidence base toward sustainable excellence in teaching and learning practices. He has published over 30 papers in this and other areas of health professions education. 


\section{Marieke van der Schaaf, Ph.D.}

Marieke van der Schaaf is a professor of Research and Development of Health Professions Education at University Medical Center Utrecht. As an Educational Scientist, multidisciplinarity, inclusion and innovation are key elements of her approach. She is director of the Center for Research and Development of Education at the Education Center at University Medical Center Utrecht. Before she was a director of the Masters Program Educational Sciences and a researcher, lecturer and course coordinator at the Department of Education, Utrecht University. Her research focuses on performance assessment, feedback and teacher expertise development in education and at the workplace. She led several international research projects in this field and she has been a supervisor of many (under)graduate and Ph.D.-students in these themes. She has over 30 publications in health sciences education.

Finally, we have to report one more departure. After 25 years as editor in chief, and 48 years in medical education, I have decided to hand over the editorship, effective next spring. It is a nice round number-the year is 2020 , the journal will be 25 years old, and I will be 75 years old.

To that end we established a search committee chaired by Cynthia Whiteside, last August. They made their selection in April. Rachel Ellaway, University of Calgary will take over as editor in chief effective issue 25:1. I am confident the journal is in good hands.

As for me, I fear that after all this time, my DNA contains a research mutation, so I will be carrying on with my research on reasoning. I look forward to seeing everyone many times in the future.

Publisher's Note Springer Nature remains neutral with regard to jurisdictional claims in published maps and institutional affiliations. 